\title{
O envolvimento dos estudantes em aulas de Ciências por meio da linguagem narrativa das histórias em quadrinhos
}

\author{
The involvement of students in science classes through the \\ narrative language of comics
}

\author{
Adriana A. D. Rodrigues e Ana L. de Quadros
}

Resumo: A busca por estratégias que atraiam a atenção dos estudantes para o conteúdo desenvolvido em sala de aula e que os envolvam com a Ciência tem sido um desafio para professores. Neste trabalho planejamos e desenvolvemos um conjunto de atividades relacionadas a uma história em quadrinhos (HQ) autoral, envolvendo o conceito de densidade. $\mathrm{O}$ objetivo foi investigar como a linguagem narrativa ilustrada pode contribuir no envolvimento dos estudantes com o conhecimento científico desenvolvido nas aulas de Ciências/Química e, assim, contribuir para a aprendizagem. Para tal, as aulas foram filmadas e duas questões problema foram propostas aos estudantes, uma logo após a leitura da HQ e outra aproximadamente três meses depois. A análise se pautou nos estudos de Jerome Bruner e foi realizada considerando tanto o envolvimento dos estudantes com a narrativa presente na HQ quanto as proposições feitas para a resolução das questões-problema. Observamos estudantes interessados nas aulas e percebemos que elementos presentes na história se mantiveram na memória durante todo o processo da pesquisa. Argumentamos que histórias em quadrinhos são instrumentos eficazes para interessar os estudantes na discussão de um conceito, auxiliando-os a fazer relações desse conceito com o contexto em que estão inseridos e, assim, facilitar a aprendizagem.

Palavras-chave: Histórias em Quadrinhos. Narrativa. Ensino de Química.

\begin{abstract}
The motivation underlying this study was to look for strategies that attracted the students' attention to the content taught in the classroom and to engage them in science. In this work we planned and developed a set of activities related to a comic (HQ) involving the concept of density. The objective was to investigate how illustrated narrative language can contribute to student involvement with Science/Chemistry classes. For this, the classes were filmed and two problem questions were proposed to the students, one after reading the comic and another about 3 months after. The analysis was performed considering the students' involvement with the narrative present in the HQ and the propositions made to solve the problem questions. We observed students interested in class and we realized that the elements in the story were kept in students' memory throughout the research process. We argue that comics are effective tools to give students an interest in discussing a concept, helping them to relate concept to context and thus facilitate learning.
\end{abstract}

Keywords: Comics. Narrative. Chemistry Teaching.

Adriana Araújo Dutra Rodrigues (adrianaadrodrigues@gmail.com) é professora de Química da rede pública de Minas Gerais. Mestre em Educação pela UFMG e Licenciada em Química pela UFMG. Atua na produção de tirinhas e HQs, como as disponíveis em http://bramevlad.blogspot.com.br/. Belo Horizonte, MG - BR. Ana Luiza de Quadros (aquadros@qui.ufmg.br) é professora Adjunta de Ensino de Química no Departamento de Química/ICEX, da Universidade Federal de Minas Gerais e do Programa de Pós-Graduação em Educação da Faculdade de Educação da UFMG. Doutora em Educação pela UFMG, Mestre em Educação nas Ciências pela UNIJUÍ, Licenciada em Química pela UNIJUÍ. Belo Horizonte, MG - BR.

Recebido em 23/08/2017, aceito em 01/03/2018

A seção "Cadernos de Pesquisa" é um espaço dedicado exclusivamente para artigos inéditos (empíricos, de revisão ou teóricos) que apresentem profundidade teórico-metodológica, gerem conhecimentos novos para a área e contribuições para o avanço da pesquisa em Ensino de Química. 
Publicações em revistas especializadas da área (Chinelli et al., 2010; Malafaia et al., 2010; entre outros) têm alertado para o pouco interesse dos estudantes pelas ciências básicas ensinadas nas escolas. A busca por estratégias que atraiam a atenção dos estudantes para o conteúdo desenvolvido em sala de aula e que os envolvam nas aulas de Ciências é uma constante no trabalho do professor, já que esse envolvimento pode favorecer a aprendizagem. Em uma época de tantos estímulos exteriores - como a internet e os artefatos eletrônicos - atrair a atenção dos jovens para a Ciência é um desafio.

Diante das evidências de pouco interesse, um fato merece destaque: grande parte dos jovens aprecia quadrinhos e dedica tempo a essa leitura. Evidência disso é o grande número de publicações do gênero, disponíveis tanto em bancas quanto na internet. Essas publicações representam um meio no qual o visual e o literário se tocam, ganhando novas nuances e uma nova forma de expressão.

Experiências anteriores com a produção de quadrinhos em blog ${ }^{1}$ e em fanzine ${ }^{2}$ nos levaram a considerar as histórias em quadrinhos como potenciais atividades de envolvimento de estudantes nas aulas. Nessas experiências os estudantes se mostraram atraídos por esse tipo de atividade. Sendo assim, este trabalho foi desenvolvido com o objetivo de investigar como a linguagem narrativa ilustrada pode contribuir para o envolvimento dos estudantes com as aulas de Ciências (particularmente, de Química). A partir de uma História em Quadrinhos construída por uma das autoras e utilizada em aulas de Química, nos propusemos a investigar as seguintes questões de pesquisa: a) Qual a contribuição dos quadrinhos para o ensino de conceitos científicos?; b) A inserção de histórias em quadrinhos nas aulas de Química predispõe o estudante a se apropriar de um conceito?; c) A linguagem presente na história em quadrinhos permeia o ensino a ponto de ser relembrada mais tarde, em um contexto avaliativo?

\section{Visitando a Literatura}

\section{a) A Ciência escolar e os quadrinhos}

Segundo McCloud (1995), uma história em quadrinhos pode ser definida como uma "sequência de imagens pictóricas justapostas em uma ordem deliberada". Essa definição abrange diversas obras de arte ao longo da história da humanidade, como afrescos egípcios, códices mexicanos e tapeçarias medievais, ao mesmo tempo que diferencia os quadrinhos das ilustrações, charges e cartuns (que não usam imagens justapostas), ou de padrões e mosaicos, nos quais as imagens justapostas podem ter a ordem alterada sem que haja prejuízo à obra. $\mathrm{O}$ formato atual dos quadrinhos, entretanto, tem suas raízes no século XIX, com os trabalhos de Töpffer e Agostini (Coupiere et al., 1970).

Inicialmente considerados como diversão para crianças, por meio de pesquisa desenvolvida por Coupiere et al. (1970), percebeu-se que parte considerável dos apreciadores de quadrinhos era formada por pessoas em torno dos 30 anos e de elevada formação intelectual. Mesmo com essa diversidade de apreciadores, até meados dos anos 80 , as histórias em quadrinhos dificilmente eram vistas como algo que tivesse um valor educacional relevante (Pizarro, 2009a).

Foi a crescente adoção das histórias em quadrinhos por várias esferas sociais que levou os educadores a refletirem sobre seu uso em sala de aula como instrumento de ensino (Pizarro, 2009a). De maneira geral, o uso de quadrinhos na educação tem sido mais utilizado pelas Ciências Humanas (Vergueiro e Ramos, 2009). Recentemente, entretanto, os bons resultados obtidos nessas áreas do conhecimento têm atraído os professores brasileiros ligados às áreas de Ciências Exatas $\mathrm{e}$ da Natureza, que começam a refletir sobre como os quadrinhos podem ser úteis em suas disciplinas (Caruso e Silveira, 2009). Essas reflexões têm sido feitas principalmente nos últimos dez anos, mas ainda há relativamente pouco material disponível em português, para a área de Química (Santos e Aquino, 2010).

\section{b) As HQs no Ensino de Química no Brasil}

Vergueiro e Santos (2012) afirmam que a Lei de Diretrizes e Bases da Educação Nacional foi o marco principal da aceitação dessa mídia no panorama educacional. Inicialmente, as pesquisas a respeito do uso de HQs na educação estiveram mais restritas às Ciências Humanas, especialmente nas áreas de Linguagem e História. Livros como Quadrinhos na Educação (Vergueiro e Ramos, 2009), por exemplo, focam mais em discutir adaptações dos clássicos literários para os quadrinhos, utilizando-os para promover a compreensão da linguagem e a interpretação sociocultural.

Fizemos uma busca por trabalhos relacionados ao uso de HQs em sala de aula no Portal de Periódicos da Coordenação de Aperfeiçoamento de Pessoal de Nível Superior (Portal CAPES), usando as palavras-chave "quadrinhos" e "comics" (o termo em inglês para quadrinhos). Para isso consideramos apenas os trabalhos avaliados por pares e o período de 2009 a 2014. Obtivemos um total de 34 resultados, mas nenhum deles versava sobre o uso de HQs nas salas de aula, como recurso didático.

Optamos, então, pelos anais de dois eventos tradicionais na área do Ensino de Química/Ciências, durante o período de 2009 a 2014. Um dos eventos foi o Encontro Nacional de Pesquisa em Educação em Ciências (ENPEC), que engloba pesquisadores da área de ensino de Ciências (Física, Biologia e Química, entre outras) e que ocorre nos anos ímpares. O outro foi o Encontro Nacional do Ensino de Química (ENEQ), que congrega a comunidade de pesquisadores em Ensino de Química e ocorre nos anos pares. Esses eventos têm uma expressiva participação de pesquisadores da área, podendo ser considerado uma representação das pesquisas realizadas na área.

No evento ENPEC, nos anos pesquisados, foram apresentados 20 trabalhos com a temática Quadrinhos (quatro em 2009, seis em 2011 e dez em 2013), sendo que seis deles usaram HQs em salas de aula de Ciências. Notamos, porém, que apenas um deles versava sobre o uso de HQs no Ensino de Química. 
Trata-se do planejamento e desenvolvimento de uma sequência didática na qual foi usada uma HQ de Maurício de Sousa sobre reciclagem (Pizarro et al., 2011). Segundo os autores, o trabalho teve repercussões positivas na educação ambiental dos estudantes, que também apresentaram, em sua maioria, bom resultado na avaliação.

Já no Encontro Nacional do Ensino de Química (ENEQ), no período de 2010 a 2016, foram apresentados 35 trabalhos, sendo cinco em 2010, três em 2012, quinze em 2014 e doze em 2016. No ano de 2014 aconteceu, inclusive, uma sessão coordenada sobre HQ, o que mostra um aumento de interesse pela temática. Notamos, no evento ENEQ, um aumento de trabalhos envolvendo HQs produzidas especialmente para o uso em sala de aula (Santos et al., 2010; Uchôa e Francisco Junior, 2012; Gama e Francisco Junior, 2014; Santos et al., 2014; Rodrigues e Quadros, 2014; Miguêz et al., 2016), incluindo uma produção de quadrinhos táteis, para estudantes com deficiência visual (Oliveira et al., 2010). Ao que nos parece, a tendência é de que trabalhos com essa temática se façam mais presentes nos próximos eventos e, talvez, nas publicações em periódicos científicos.

Mesmo considerando o aumento de interesse dos educadores sobre o tema $\mathrm{HQ}$, as pesquisas que avaliam o impacto dessa mídia na escola ainda são poucas. Encontramos, no banco de teses e dissertações da Biblioteca Nacional, duas dissertações envolvendo o tema (Testoni, 2004; Pizarro, 2009a) e na rede mundial de computadores (internet) uma terceira, oriunda de Portugal (Soares, 2004). Descrevemos, brevemente, esses três trabalhos.

Soares (2004) investigou como estudantes e professores lidam com as informações contidas nos quadrinhos. Ela forneceu aos estudantes, em aulas de Química, excertos de HQ do Tio Patinhas e do Asterix, que citam conceitos químicos (exemplo na Figura 1). Após lidar com essas HQs, os estudantes responderam questionários que avaliaram como eles lidavam com as informações contidas nos quadrinhos. O mesmo trabalho avaliou se os professores eram capazes de compreender o potencial desses quadrinhos para o ensino.
A pesquisadora afirma que os estudantes têm dificuldades, ao ler uma $\mathrm{HQ}$, de encará-la criticamente, e confiam no que está sendo apresentado, mesmo quando o conteúdo dos quadrinhos contradiga assunto já trabalhado em uma aula. Os argumentos usados pela autora nos levam a perceber que a HQ pode reforçar concepções alternativas ou até mesmo criá-las. Sendo assim, a pesquisadora afirma que discutir quadrinhos com temas científicos em sala de aula não só tem o potencial de detectar e discutir as concepções alternativas dos estudantes, como reforça que a informação científica veiculada em quadrinhos é uma forma poderosa de aprendizagem.

No mesmo ano, no Brasil, Testoni (2004) se apoia na teoria da equilibração de Piaget e na mudança conceitual para investigar as HQs. Ele apresenta aos estudantes uma HQ instigadora que propõe uma situação-problema e estuda o impacto da mesma na mudança conceitual dos estudantes em uma aula de Física. Após a leitura e discussão da HQ, os estudantes produziram seus próprios quadrinhos sobre o tema.

Os estudantes foram avaliados por meio das HQs que criaram e de questionários. Testoni (2004) afirma que a HQ representa "a faísca de uma explosão", ou seja, o fator desencadeador de discussões a respeito de um tema proposto (p. 124). Ele reforça a postura mediadora que o professor deve assumir em sala de aula, mesmo em uma atividade na qual os estudantes costumam se envolver mais. A inserção ou a valorização dos conceitos científicos não ocorre espontaneamente e, nesse sentido, o professor deve estar preparado para fazer a mediação.

Pizarro (2009a) analisa a forma de se utilizar a HQ em sala de aula. Sua pesquisa envolve estudantes da quarta série do Ensino Fundamental usando, em aulas de Ciências, quadrinhos da Turma da Mônica. Os quadrinhos apresentados versavam sobre temas de importância ambiental. Seu objetivo era usar as HQs como fomentadoras de discussões e reflexões sobre esses temas. Segundo ela, o uso das HQs tornou o conteúdo mais próximo e mais interessante aos estudantes, com a ressalva de que, sem o ensino de conteúdos procedimentais tais como ler, redigir, identificar, descrever, relatar oralmente, comparar,
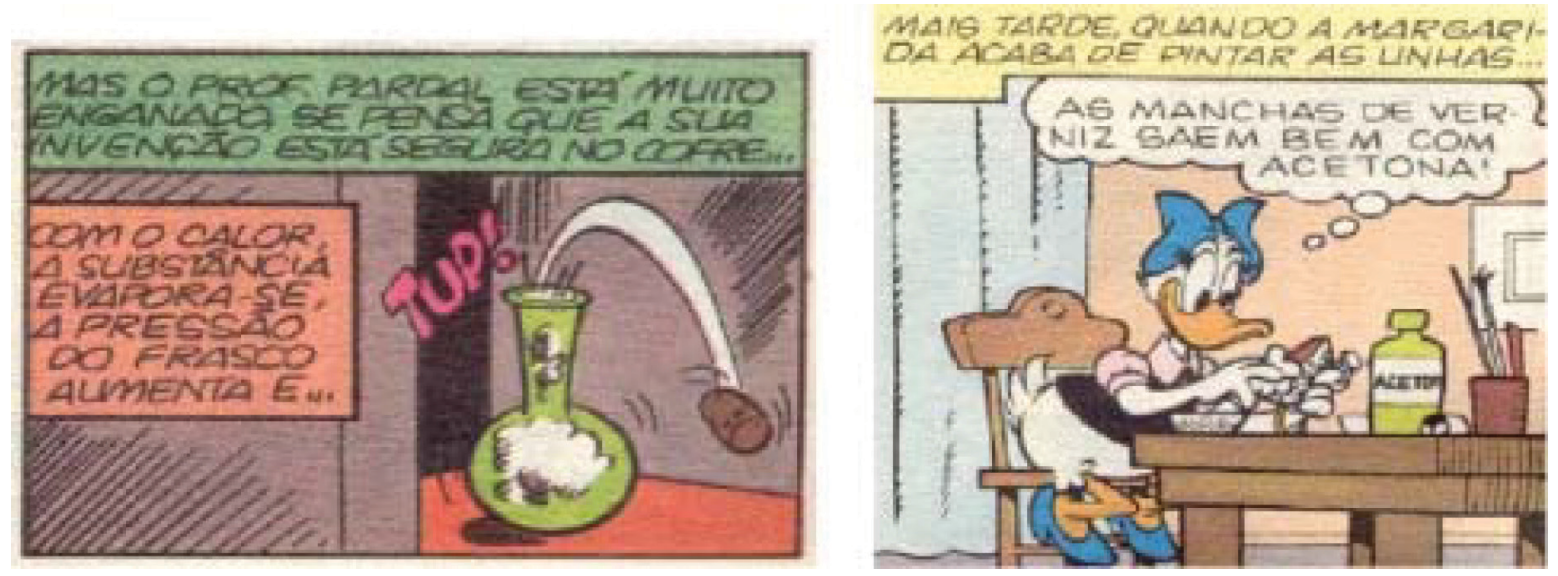

Figura 1: Quadrinhos do "Tio Patinhas”, usados por Soares (2004). Fonte: Soares (2004, p. 171 e 160). 
relacionar, classificar, etc., não é possível colher os benefícios da prática.

A pesquisadora é enfática ao alertar sobre a necessidade de se planejar a aula em função do uso da HQ em vez de simplesmente usá-la como um complemento. As aulas envolvendo HQs, segundo Pizarro (2009a), devem ser orientadas por objetivos bem delineados.

Podemos perceber, por meio das pesquisas descritas, que a introdução dos quadrinhos parece ter dinamizado as aulas e enriquecido a experiência dos estudantes, predispondo-os ao aprendizado. Ainda assim, permanecem questões que envolvem a utilização de HQs e a contribuição delas no aprendizado, o que justifica a realização de novas pesquisas.

\section{c) A narrativa e os quadrinhos}

Will Eisner, considerado um dos mais importantes quadrinistas dos EUA, em seu livro Quadrinhos e Arte Sequencial, define essa forma de arte, dizendo "Quadrinhos se comunicam em uma linguagem que depende de uma experiência visual comum entre o criador e o público" (Eisner, 1985, p. 7). Para ele, a atividade de ler quadrinhos é semelhante à leitura de um texto: as mesmas habilidades de decodificação de símbolos são utilizadas para ambas as tarefas, sendo que os leitores dos quadrinhos ainda trabalham com duas formas de símbolos: as palavras, com todas as convenções do gênero literário (gramática, trama, sintaxe) e as imagens, com todas as convenções do gênero visual (como perspectiva, simetria, imagens que representam movimentos, etc.).

Baseadas em Eisner (1985), julgamos possível lidar com as histórias em quadrinhos de forma semelhante à maneira como se lidaria com uma mídia escrita, do ponto de vista estritamente narrativo. Nesse sentido, nos apropriamos das obras de Bruner (1991, 1997, 2001, 2002 e 2010), por conta de seu extenso tratamento da linguagem narrativa. Bruner (1997 e 2002) trata de dois modos de linguagem: o modo paradigmático e o modo narrativo.

O modo paradigmático se baseia em um sistema de categorias idealizadas, relacionadas umas com as outras em um sistema regido pela lógica matemática. As afirmações feitas nesse modo são claras e livres de subentendidos, alcançando conclusões verificáveis e generalizáveis. As histórias contadas por esse modo tendem a ser pontos de partida ou proposições teóricas, que serão amadurecidas até se tornarem argumentos verificáveis. Aqui, a legitimidade do argumento é alcançada pela consistência do mesmo. Assim, essa linguagem implica a existência de uma verdade universal que pode ser comunicada inequivocamente.

A linguagem paradigmática está, geralmente, presente nos livros didáticos, nos artigos científicos, nos relatórios técnicos e outras publicações de caráter científico. Em função disso, nas salas de aula, particularmente as aulas de Ciências, essa tende a ser a linguagem que os professores buscam utilizar e desenvolver nos estudantes. O modo de linguagem que os estudantes utilizam em suas interações diárias, entretanto, é outro.
O modo narrativo pode ser definido como aquele que lida com as intenções humanas e suas vicissitudes. Em vez de se firmar em argumentos, a narração se preocupa com as condições humanas. Ela se torna legítima não por ser verdadeira, mas por ser verossímil, isto é, por retratar com autenticidade o ser humano e sua consciência. Segundo Bruner, "pode ser que as condições e os estados intencionais descritos em uma ficção 'bem-sucedida' nos sensibilizem a experimentar nossa própria vida de maneira semelhante" (Bruner, 1991, p. 12).

Ao comparar os dois modos de pensamento, Bruner (2010) afirma que ambos - narrativo e paradigmático - não só podem conviver em harmonia, como se complementam ativamente. Se, por um lado, o modo paradigmático busca formar teorias que se ajustem a fatos observados, por outro, nós costumamos conceber um mundo no qual caibam as histórias que contamos a seu respeito.

Voltando à linguagem narrativa, esse autor apresenta inúmeras características para ela, das quais destacaremos três, que consideramos úteis para este trabalho: (1) sua sequencialidade - isso é, ser composta de uma sequência intencional de fatos; (2) não necessariamente se prender à realidade do fato narrado (isso é, ser verossímil, mas não necessariamente verdadeira, como já dito) e; (3) sua capacidade de, nas palavras de Bruner (1997, p. 50), "encontrar um estado intencional que atenue ou pelo menos torne compreensível um afastamento de um padrão cultural canônico". Nesse caso, a narrativa torna possível a explicação de algo que se afasta do esperado pelo interlocutor.

Por conta dessa terceira característica, na linguagem narrativa não só é permitida a subversão dos operadores de lógica da linguagem, como também é, às vezes, esperado que isso aconteça (como no recurso da ironia, em que uma determinada frase, em determinado contexto narrativo, tem significado oposto ao que está expresso nas palavras).

Para Bruner (2010), a narrativa parte de uma situação de estabilidade e, após a frustração das intenções dos personagens, alcança uma situação de crise. $O$ final pode ou não trazer uma nova situação estável. Essas histórias acontecem, basicamente, em dois planos: o panorama da ação (a história propriamente dita, seu contexto, pano de fundo e personagens) e o panorama da consciência (as motivações e os sentimentos dos personagens). Para ele, uma narrativa "bem formada" seria "composta pelo quinteto: um Ator, uma Meta, um Cenário e um Instrumento, além de um Problema" (Bruner, 1997, p. 51). Além disso, ela apresenta uma "paisagem dual", que é o contraste entre o mundo presumivelmente real onde a narrativa se desenvolve e o mundo mental do protagonista.

Segundo Bruner (2002), a leitura de uma narração é uma atividade imensamente interativa e particular. Ao ler uma narração, o leitor cria em sua mente sua própria versão da história, a que esse autor chama de texto virtual. Ele discute outras três características da narração, além das já citadas, para mostrar como elas agem para "alistar" o leitor na escrita de seu texto virtual: a pressuposição, a sujeitificação e a perspectiva múltipla. 
Pressuposições são criadas pelo texto com o uso de determinados "gatilhos", de forma a fazer a narrativa dizer mais com menos palavras. Por exemplo, quando um personagem pergunta a outro "você viu o unicórnio entrar?", a narrativa parte do pressuposto de que, para aquele personagem, unicórnios existem e são visíveis. Se um personagem pede a outro que apague a luz, pressupõe-se que a luz estava acesa naquele ambiente e assim sucessivamente.

A sujeitificação é a apresentação da realidade da narrativa através da lente criada pela consciência do protagonista. Nas narrativas onde ela ocorre, o narrador não se preocupa em estabelecer uma perspectiva imparcial do mundo, mas o apresenta acompanhado das ações e percepções do personagem. Por exemplo, na história de João e Maria, a casa de doces no meio da floresta não é apresentada aos leitores pelo narrador como estranha, não-natural ou suspeita, mas como atraente e irresistível - tal qual os protagonistas, duas crianças, a percebem.

A perspectiva múltipla é a capacidade que a narração tem de apresentar o mesmo fato sob vários prismas, para enriquecer seu significado. Um exemplo é a série de livros Crônicas de Gelo e Fogo, que deu origem à famosa série de TV Game of Thrones. A história dos livros é formada por vários capítulos, e cada um deles é narrado pelo ponto de vista de um personagem. Esses capítulos frequentemente mostram o mesmo acontecimento, mas sob a ótica de pessoas diferentes, mudando a percepção do leitor sobre aquele fato.

Essas três características permitem ao leitor criar sua própria realidade ao ler um relato, levando para ela sua estratégia de leitura e seu repertório de interpretações. Uma história de sucesso seria aquela que contém situações humanas difíceis que engajam o interesse do leitor e permitem que ele possa criar seu texto virtual com alguma liberdade. Afinal, para Bruner, "o ato do autor, ao criar uma narrativa de um determinado tipo e de forma especial não é evocar uma reação padronizada, mas recrutar o que for mais apropriado e emocionalmente vívido no repertório do leitor" (Bruner, 2002, p. 37).

Bruner (2002) relata, ainda, experimentos que o levaram a concluir que o processo de criação de um texto virtual não se restringe ao leitor de histórias ficcionais, mas é parte integrante de como o ser humano reage ao mundo. Quando pessoas estão observando determinada situação, depois de reconhecer certo número de elementos familiares - os gatilhos - elas enquadram essa situação em suas teorias pessoais de mundo.

Para exemplificar, usamos um experimento narrado por Bruner. Ele se constituía de cartas de baralho sendo mostradas a voluntários por alguns milésimos de segundo, dentro de um projetor de imagens. Os voluntários deveriam então dizer qual carta haviam visto. Entre essas cartas havia algumas "cartas impossíveis" (como cartas de paus vermelhas ou cartas de ouros pretas, por exemplo). Em vez de reconhecê-las como tal, os sujeitos submetidos ao experimento tentavam enquadrá-las no padrão conhecido das cartas de baralho. Um desses sujeitos chegou a dizer que um seis de paus vermelho não era realmente vermelho, apenas parecia assim por conta da iluminação do projetor, negando a própria evidência de seus olhos.

Bruner (2002) arremata essa experiência dizendo que:

o que os observadores humanos fazem é apanhar quaisquer fragmentos que possam extrair do input de estímulo e, se estes estiverem de acordo com suas expectativas, ler o resto a partir do modelo que têm em sua cabeça (Bruner, 2002, p. 50).

Por fim, Bruner (1997) também discute a narrativa como forma de organizar a experiência dos seres humanos. Ele busca o trabalho de Jean Mandler (Mandler, 1984, apud Bruner, 1997) como evidência de que aquilo que a mente não estrutura narrativamente sofrerá perdas ao ser armazenado na memória. Ele também recorre a Bartlett (Bartlett, 1932, apud Bruner, 1997), explicando que a memória é uma reconstrução do passado sobre atitudes de afeto, que busca justificar essas atitudes.

Ampliando a ideia para levar em conta a construção social da memória em vez de uma visão mais individualista, Bruner (1997) conclui que a reconstrução da memória é também dialógica: quando uma pessoa vocaliza a memória, seu interlocutor (real ou abstrato) faz uma pressão sutil, de forma que as memórias relatadas façam sentido para os dois participantes do diálogo.

Bruner (2001) fornece subsídios que nos permitem trazer essa discussão para o ensino das Ciências. Segundo ele:

dedicamos uma quantidade enorme de esforço pedagógico para ensinar os métodos da ciência e o pensamento racional: o que está envolvido na verificação, o que constitui contradição, como transformar meros enunciados em proposições testáveis, e assim por diante (Bruner, 2001, p. 141).

Em outras palavras, o ensino de Ciências está preocupado em ensinar aos estudantes os fundamentos do modo paradigmático. Porém, as narrativas são parte de como o ser humano experimenta a vida e como ele mantém essa experiência para si. Sendo assim, o ensino de Ciências poderia se beneficiar de narrativas que insiram essa realidade científica na narrativa de vida do estudante, para só então buscar outros modos de linguagem. Consideramos que é essa a função das HQs, já que são primariamente um meio narrativo.

Portanto, as HQs não são simplesmente um meio mais atrativo de apresentar os conceitos científicos, mas uma oportunidade de auxiliar os estudantes na criação de uma narrativa interior que acomode melhor esses conceitos, facilitando a compreensão e a memória dessa experiência de aprendizado. Quando os estudantes são apresentados a uma narrativa, é esperado que se identifiquem com as vicissitudes dos personagens e proponham estratégias para a resolução do problema proposto. Ao associarmos essas vicissitudes a 
um conceito científico, o estudante buscará compreender o conceito não para seu ganho pessoal, mas para que a solução da história seja aceitável a seus olhos e o conflito humano seja satisfatoriamente resolvido. Ao terminar de ler a narrativa, na pior das hipóteses, ele terá respondida a eterna pergunta de "por que estou estudando esses conceitos novos?".

Outro ponto interessante diz respeito à forma como a narração ajuda as pessoas a, nas palavras de Bruner (2010), "domesticar o imprevisto". Consideramos que a necessidade de explicar o imprevisto ou aquilo que foge do canônico pode se configurar em uma boa possibilidade de se apropriar de conceitos científicos, de maneira mais natural, diminuindo as dificuldades que o estudante possa ter ao se confrontar pela primeira vez com um conceito para ele abstrato e desconhecido. Se estiver engajado na história, acreditamos que esse estudante poderá mais facilmente acomodar determinado conceito à sua própria experiência de mundo, abrindo caminho para um aprendizado mais significativo.

Partimos da hipótese de que a HQ, como uma forma de narrativa, pode auxiliar no envolvimento do estudante com os conceitos científicos geralmente desenvolvidos nas aulas de Ciências. Com isso, organizamos os passos metodológicos que nos auxiliaram a investigar essa hipótese.

\section{Metodologia}

Desenvolvemos esta investigação com os objetivos de investigar o impacto dos quadrinhos para o ensino e aprendizagem de conceitos químicos, e se a trama de uma HQ permanece na memória dos estudantes a ponto de ser relembrada em um processo avaliativo formal da escola.

A pesquisa realizada tem características de pesquisa qualitativa, já que investiga um fenômeno que não é passível de ser medido quantitativamente, como é o caso de uma crença, uma representação, um estilo pessoal de relação com o outro, uma estratégia em face de um problema, um procedimento de decisão, entre outros. Os métodos qualitativos de pesquisa são descritos, portanto, como modelos diferenciados de abordagem empírica e são voltados especificamente para os chamados "fenômenos humanos" (Mucchielli, 1991). Porém, como o termo "qualitativo" é muito amplo e genérico, é conveniente usar denominações mais precisas. Assim, dentre os principais tipos de pesquisa qualitativa, esta assume características de estudo de caso. Segundo Lüdke e André (1986, p. 17), o estudo de caso é usado quando o pesquisador tem interesse em pesquisar um fenômeno particular. Sobre esse método, elas afirmam que "o caso é sempre bem delimitado, devendo ter seus contornos claramente definidos no desenvolver do estudo". Yin (2005) alerta que, mesmo se tratando de um caso único, é possível se fazer generalizações.

Inicialmente produzimos uma HQ especificamente para esse fim, como problematizadora de uma unidade de conteúdo. ${ }^{3}$ Essa história envolveu o conceito de densidade, que orienta a narrativa na forma de quadrinhos. Nessa história, duas meninas são visitadas por uma amiga, que tem um problema: ela tem uma pequena estátua de ouro, que pode ter sido falsificada. As meninas (que têm 13 anos) invadem o laboratório particular do pai de uma delas, com o desafio de descobrir se a estátua é ou não de ouro. Porém, elas não têm acesso à maior parte dos equipamentos.

Elas resolvem a situação utilizando algumas moedas de ouro da coleção do pai, medindo a massa das mesmas e acrescentando novas moedas à pilha até que tenham massa de ouro semelhante à massa da estátua. Então, elas mergulham a estátua e as moedas em frascos semelhantes a uma proveta, mas não volumétricos. Os frascos possuem o mesmo volume de água, para que as meninas pudessem comparar o volume de água deslocado pelas moedas e pela estátua. Com essa estratégia elas foram capazes de solucionar o problema.

Os desenhos foram feitos a mão e receberam um contorno com caneta nanquim descartável. A colorização (em escalas de cinza) e o letreiramento foram feitos no programa de edição de imagens GIMP ${ }^{\circledR}$. A validação do roteiro foi realizada com uma turma de estudantes de uma escola diferente daquela em que foram desenvolvidas as aulas, com a intenção de verificar a compreensão da história e do conceito a ser explorado. Somente após a validação, a HQ foi usada na pesquisa aqui relatada.

Esse trabalho envolveu uma turma de 25 estudantes do primeiro ano do Ensino Médio de uma escola pública de Belo Horizonte, MG. A faixa etária desses estudantes variava entre 14 a 18 anos. Tanto nas aulas de Química como em outras disciplinas do currículo escolar, esses estudantes eram considerados pouco participativos nas aulas. Essa "pouca participação" foi pontuada em conversas com todos os professores que são responsáveis por alguma disciplina do currículo e que tinham contato frequente com esses estudantes por meio de aulas. Embora tenha um caráter totalmente subjetivo, levamos em consideração por ser a mesma opinião relatada por todos os professores que, no semestre em que foi realizada essa investigação, ministravam aulas para essa turma de estudantes.

A atividade aconteceu nas seguintes etapas:

1) Desenvolvimento da HQ, na turma selecionada, seguida de uma situação-problema;

2) Avaliação escrita com uma questão remetendo ao tema da HQ;

3) Reconstrução da resposta fornecida na avaliação escrita, em grupo.

As aulas foram gravadas em vídeo e os episódios relevantes foram transcritos. Optamos, ao transcrever algumas respostas, por identificar os estudantes por letras, com a intenção de preservar suas identidades. Para diminuir a influência da câmera na participação dos estudantes, duas aulas anteriores ao processo também foram filmadas. Com isso, esperávamos criar um ambiente em que a filmadora tivesse uma interferência mínima, familiarizando os estudantes com essa presença. 
A análise dessas atividades foi feita considerando tanto o envolvimento dos estudantes com a narrativa presente na HQ quanto as proposições feitas para a resolução da questão-problema principal, nos dois momentos em que se realizou. As categorias usadas nessa análise surgiram a partir dos dados. Isso significa que agrupamos as respostas por semelhança e construímos categorias que pudessem englobar essas respostas. Essas categorias foram, portanto, fundamentada nos dados (Glaser e Strauss, 1967). Os 25 estudantes foram identificados por letras e, quando fizemos transcrições de falas ou de texto escrito, a identificação foi feita usando a palavra Estudante seguida da letra que o identificou (por exemplo: Estudante A).

\section{Resultados e Discussão}

A História em Quadrinhos produzida foi apresentada aos estudantes em uma aula de Química, ao final do segundo bimestre letivo. No primeiro momento da aula foi feita a leitura da HQ, individualmente ou em duplas. Após a leitura, a professora levou os estudantes a retomarem a história instigando-os com perguntas, com a intenção de sondar elementos do "texto virtual" criado por eles a partir da leitura da HQ, se baseando em estratégia usada por Bruner (2002). Em seguida, foi apresentada aos estudantes uma situação-problema semelhante à encontrada pelos personagens da história: tratava-se de eles proporem um método para identificar se um objeto era de ouro, nesse caso usando apenas materiais disponíveis no laboratório de Química da escola. Essa etapa teve como objetivo estabelecer a conexão entre o conceito químico e a narrativa da história. A determinação da massa do objeto foi logo sugerida e aceita por praticamente todos eles. No entanto, por várias vezes, os estudantes sugeriram o uso de moedas de ouro. Nesses momentos, eram lembrados, pela professora ou por um colega, que o laboratório da escola não tinha esse material. A atividade foi encerrada quando uma estudante, ao final da aula, apontou que poderia ser usada uma proveta volumétrica para determinação do volume do objeto, uma vez que a massa do mesmo já havia sido mensurada em uma balança semianalítica e a densidade do ouro era conhecida.

Ao longo de toda a discussão, a presença da HQ foi muito marcante, o que pôde ser evidenciado pelo fato de que os estudantes se reportaram insistentemente ao uso de moedas de ouro. Quando solicitados a considerar os conceitos químicos, eles se reportaram a dados incluídos na história, conforme excerto da HQ contido na Figura 2, mesmo sem mostrar um entendimento de como esses conceitos se relacionavam com o enredo ou com a solução da situação-problema.

Transcrevemos pequenos fragmentos de diálogo, para dar uma ideia do que os estudantes estavam propondo como possibilidade de identificar se a estátua em questão era de ouro usando apenas os materiais presentes no laboratório de Química da escola. Logo que foi proposto o problema, acontece o seguinte diálogo:

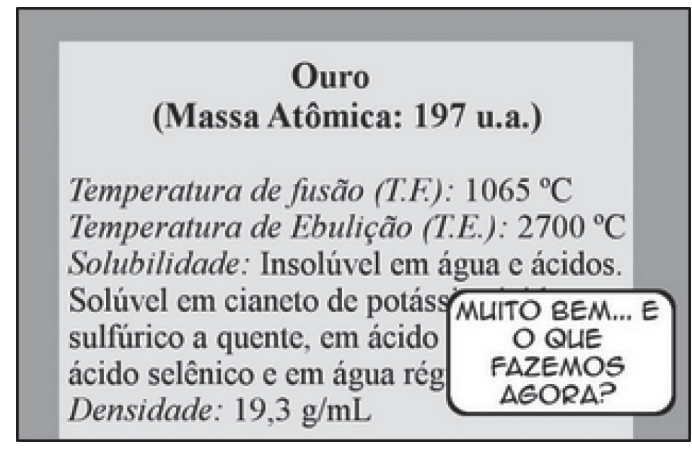

Figura 2: Excerto da $\mathrm{HQ}$ que continha os conceitos científicos. Fonte: http://bramevlad.blogspot.com.br/2017/06/alice-e-estatua-misteriosa. html

Estudante K: A gente pode fazer a mesma coisa que elas.

Professora: E vocês têm moedas de ouro?

Estudante K: Eu tenho na bolsa (risadas).

Professora: No laboratório não tem!

Estudante B: Mas nós também não temos uma estátua!

Sabemos que a linguagem paradigmática busca formar teorias que se ajustem aos fatos. O Estudante B mostra que situou o problema lançado pela professora na história que havia lido. Quando a professora mostra a impossibilidade da solução pensada por ele, rapidamente ele mostra que a situação proposta também não é possível, por não ser real. Nesse caso, ele concebeu um mundo a partir da história lida e uma solução para o problema, oriunda desse mundo imaginado. Uma solução real, que o tirava do mundo que havia construído, foi imediatamente vinculada a um problema que deveria ser real, na perspectiva dele.

Passados cerca de 8 minutos após a intervenção da professora à proposta da Estudante $\mathrm{K}$ e a afirmação do Estudante $\mathrm{B}$ de que também não tinham a estátua, o Estudante $M$ volta à questão das moedas, indagando Mas não tem moeda de ouro?. Ao que nos parece, ele criou um pressuposto (Bruner, 2002) de que as moedas de ouro sempre estarão presentes, já que as considera como condição indispensável para solucionar um problema real.

Selecionamos outros fragmentos da discussão ocorrida nesse momento da aula, em que uma solução para o problema era pensada coletivamente.

Estudante K: Professora olha! O ouro tem massa atômica 197. A gente não tinha que pegar alguma coisa que tem a massa atômica...

Professora: E como isso vai ajudar? De que adianta saber essa massa nesse momento?

[...]

Estudante W: A gente pode usar a solubilidade.

Estudante R: É..... e derreter a estátua para saber o volume! 
Estudante L: E se usar essa densidade? A densidade é 19,3. Aí divide os $200 \mathrm{~g}$ por esse aí.

Estudante S: Divide $200 \mathrm{~g}$ por 19,3.

Professora: Mas você não sabe se a estátua é de ouro mesmo. Esse é o problema!

As possíveis "soluções" apontadas pelos estudantes estão sempre ancoradas na HQ. Eles apanham um fragmento da história e o usam para buscar uma solução para o problema. Nas palavras de Bruner (2002), eles leem o restante do problema a partir do modelo que constroem a partir da HQ. No momento em que o Estudante P sugeriu o cálculo para encontrar o volume, a professora já havia escrito a fórmula matemática da densidade no quadro, o que deve ter contribuído para que esse estudante pensasse em uma solução usando aquela fórmula. A professora encaminha novamente a discussão, ao falar:

Professora: Agora pensem comigo: o que falta aqui (aponta para a fórmula matemática), para a gente descobrir se a densidade da estátua é realmente 19,5 ?

Estudante B: Fazer o que as meninas fizeram mesmo. Pegar moedas que têm a mesma massa.

Inúmeras vezes tanto a professora quanto os próprios estudantes haviam ressaltado o fato de não haver moedas de ouro no laboratório de Química da escola. No entanto, essa alternativa voltava à cena sempre que os estudantes tinham dificuldade em pensar uma solução própria. Isso confirma as afirmações de Bruner (2002) sobre como as pessoas estruturam sua visão de mundo ancoradas na narrativa, e sobre como há uma resistência adicional em abandonar esse modelo, como no caso dos voluntários que insistiam que estavam enxergando errado as "cartas impossíveis" do experimento do pesquisador.

Os conceitos citados durante essa discussão foram solubilidade, temperatura de fusão e de ebulição, massa atômica e densidade. Citaram, inclusive, uma solução sugerida por uma personagem, a título de brincadeira (transformar a estátua em um cubo para medir o volume).

Ao analisarmos o vídeo dessa aula, percebemos que, ainda que a resolução do problema tenha ocupado um tempo limitado da aula, 15 dos 25 estudantes ofereceram contribuições, sempre se baseando na HQ. Esse era um comportamento pouco usual para essa turma que, segundo os professores, não costumava demonstrar esse nível de envolvimento nas aulas. Uchôa, Francisco Junior e Francisco (2012), que produziram e usarem em aula uma HQ tratando do acidente com Césio 137 ocorrido em Goiânia, na década de 1980, argumentam que o envolvimento dos estudantes ao lidarem com HQ é promovido pela linguagem diferenciada, com imagens e diálogos (p. 11). Porém, eles também ressaltam a relação direta que a HQ deve ter com os conceitos químicos que se pretende explorar.

Em nosso trabalho, acreditamos que o fato de os estudantes terem se remetido à solução proposta pelos personagens da história demonstra o quanto a narrativa presente na HQ impactou o imaginário. Apenas ao final da aula, quando a professora encaminhou a discussão relembrando os estudantes sobre o tipo de vidraria encontrada no laboratório da escola, é que a Estudante L diz: "Mas peraí, professora, o negócio da parada é de medida, não é?", enquanto gesticulava apontando para a graduação de uma proveta volumétrica. A partir dessa afirmação e da colaboração de outros dois colegas, uma solução possível foi proposta usando um frasco graduado, disponível no laboratório, para identificar o volume da estátua.

Cerca de três semanas depois da leitura e discussão da $\mathrm{HQ}$, foi realizada a segunda etapa. Junto à avaliação formal da disciplina de Química (prova escrita) foi acrescentada uma questão que continha elementos semelhantes à situação-problema da aula em que a HQ foi apresentada, com uma estátua que deveria ser de ouro, mas que poderia ter sido falsificada e, assim, ser de latão. Nessa questão estava explícito que não poderiam destruir a estátua e que poderiam usar apenas materiais disponíveis no laboratório da escola. As respostas a essa questão foram agrupadas por semelhança, as quais chamamos de categorias, resumidas no Quadro 1.

Quadro 1: Categorias de respostas dos estudantes na questão da prova

\begin{tabular}{|l|c|c|}
\hline Categorias gerais & $\begin{array}{c}\text { Categorias } \\
\text { específicas }\end{array}$ & $\begin{array}{c}\text { Número de } \\
\text { respostas }\end{array}$ \\
\hline $\begin{array}{l}\text { Violam uma das } \\
\text { condições do problema }\end{array}$ & Destroem a estátua & 2 \\
\cline { 2 - 3 } Usam o conceito chave & $\begin{array}{c}\text { Líquido } \\
\text { intermediário }\end{array}$ & 13 \\
\cline { 2 - 3 } & $\begin{array}{c}\text { Usam medida de } \\
\text { massa e volume }\end{array}$ & 1 \\
\hline Sem sentido & 3 \\
\hline
\end{tabular}

Selecionamos duas respostas que violam uma das condições do problema, ou seja, as respostas da Estudante L e do Estudante M, que estão transcritas a seguir.

"Posso colocar a estátua em um recipiente com ácido nítrico concentrado. Se ela derreter é latão e se não derreter é ouro" (Estudante $\mathrm{L}$ ).

"Poderia fazer como foi feito na história em que lemos nas aulas anteriores: medir na balança e fazer uma comparação com algo de ouro que eu tenha no laboratório, depois comparar a densidade para descobrir, usando o tubo de ensaio e a água" (Estudante M).

Essas duas respostas são representativas das expostas pelos demais estudantes que foram classificadas nesse grupo. Dois deles utilizaram caminhos que destroem a estátua e outros seis usaram as moedas de ouro presentes na $\mathrm{HQ}$, mas não 
disponíveis no laboratório da escola. Novamente os estudantes usam um fragmento da HQ e descrevem a realidade (a solução para o problema) a partir dele. Ao afirmar "algo de ouro que eu tenho no laboratório" pode-se imaginar que estão se referindo às moedas de ouro, já que os estudantes pressupõem que elas são parte integrante do problema e devem necessariamente estar disponíveis para que ele seja solucionado, ainda que não mencionadas no enunciado. É o que Bruner (2002) aponta como pressuposição a partir da narrativa.

Um grupo significativo de estudantes propôs a utilização de um líquido que tivesse densidade intermediária entre o latão e o ouro, para poder reconhecer se o material era de latão. Nesse caso, se o material testado flutuasse não seria ouro, e se afundasse, provavelmente seria. Essa categoria específica teve o maior número de respostas para a questão problema. Nenhum deles forneceu qualquer indicação de qual líquido poderia ser usado, ou se seria possível encontrá-lo na escola. A resposta do Estudante A é um exemplo dessa subcategoria.

"No laboratório, eu iria encher um tubo com um líquido entre a densidade de 9,0 g/mL e 19,2 $\mathrm{g} / \mathrm{mL}$, se o objeto por um tempo afunda é porque supostamente pode ser ouro, se flutuar é porque supostamente é latão" (Estudante A).

Apenas um estudante se utiliza das medidas de massa e volume para encontrar a densidade. Sua solução atende às duas condições propostas pelo problema, de maneira completa. A resposta do Estudante B está transcrita a seguir:

"Primeiro eu colocaria o objeto na balança para ver a massa, depois colocaria em um tubo com água para ver o volume, e usaria a fórmula $d=m / v$. Se a densidade der 19,3 g/L é ouro, se der $8,6 \mathrm{~g} / \mathrm{mL}$ é latão" (Estudante B).

Notamos que o Estudante B produziu um erro conceitual referente à unidade. Acreditamos se tratar de um descuido de escrita, e que isso não reflete no entendimento sobre o que foi solicitado.
Outras três respostas, embora trouxessem conceitos científicos, eram incompletas ou faziam pouco sentido do ponto de vista da ciência Química. Com elas não foi possível perceber se os estudantes compreenderam o problema ou se não tinham conhecimento suficiente para construir uma solução. Selecionamos uma dessas respostas, que é representativa das demais que estão nessa categoria:

"Descobrindo a densidade, a massa. Acho que você balanceava, colocando em tubos de ensaio colocando em ácido e descobrindo o volume e a massa, aí você faz a regra de 3" (Estudante $\mathrm{N}$ ).

Apesar do envolvimento dos estudantes com a HQ ser maior do que o envolvimento com as demais aulas de Química, percebemos que, ao propor uma solução para o problema presente na prova, muitos deles violaram uma das condições presentes na questão e um número expressivo usou o líquido intermediário. O conceito de densidade, que foi chave na resolução da HQ, foi apropriado por um único estudante, mas não pelos demais.

Por causa da mudança do calendário, ocorrida em função da Copa do Mundo de futebol, ${ }^{4}$ a terceira etapa foi realizada cerca de três meses depois. Para essa atividade, os estudantes foram reunidos em seis grupos, de acordo com as categorias (Quadro 1) de suas respostas na questão de prova. Os estudantes pertencentes à categoria de líquido intermediário foram divididos em dois grupos. Em grupos, eles foram instruídos a pensar novamente na situação-problema, a partir do feedback dado pela professora às respostas e a apresentar uma resposta adequada ao que foi solicitado. O Quadro 2 retrata os grupos, a quantidade de estudantes em cada um dos grupos, as categorias em que classificamos as respostas dadas à questão da prova, $\mathrm{e}$ a resposta que apresentaram ao fim da discussão nos grupos.

Dois desses grupos, os de número 2 e 4 , usaram os conceitos de massa e volume adequadamente e, assim, demonstraram domínio no uso do conceito de densidade. Os grupos 1 e 3 , durante a realização da atividade discutiram com a professora e entre si, demonstrando interesse. Porém, ao que nos parece, faltaram elementos que permitissem a eles chegar a uma explicação consensual que atendesse aos requisitos da questão, o

Quadro 2: Síntese das respostas fornecidas nas diferentes etapas do trabalho

\begin{tabular}{|c|c|c|l|}
\hline Grupo & $\mathbf{N}^{\circ}$. de Estudantes & $\begin{array}{c}\text { Categoria das respostas } \\
\text { da prova escrita }\end{array}$ & Categoria das respostas durante a conclusão da atividade \\
\hline 1 & 2 & Destroem a estátua & Usam moedas (solução da HQ) \\
\hline 2 & 6 & Usam moedas & Medida de massa e volume \\
\hline 3 & 6 & Líquido intermediário (a) & $\begin{array}{l}\text { Semelhante à das moedas (solução da HQ), mas com um bloco de } \\
\text { cobre. }\end{array}$ \\
\hline 4 & 7 & Léquido intermediário (b) & Medida de massa e volume \\
\hline 5 & 1 & Sem sentido & $\begin{array}{l}\text { Duas soluções: uma que compara dois objetos e uma que usa um } \\
\text { líquido de densidade intermediária. }\end{array}$ \\
\hline 6 & 3 & &
\end{tabular}


que, ao final, os levou a optar pelo procedimento que lhes era familiar: o da HQ. Novamente descrevem a realidade a partir da consciência do protagonista da HQ, mostrando que estão se utilizando da estrutura narrativa criada anteriormente (Bruner, 1991). O grupo 6 mostrou pouco entendimento sobre o problema proposto e, assim, não foi capaz de propor uma solução. Para esses três estudantes provavelmente seria necessária a retomada do processo de ensino.

$\mathrm{O}$ fato de 14 dos 25 estudantes terem se apropriado do conceito de densidade para resolver um problema que lhes foi proposto nos fez acreditar que a HQ teve uma contribuição importante. A resolução dessa situação-problema exigia mais do que uma memorização de conceitos. Esses estudantes, cada um a seu tempo, propuseram as medidas de massa e de volume e com elas o cálculo da densidade do material. De posse do valor da densidade desse material, eles poderiam comparar com os valores de densidade do ouro e do latão, presentes na questão proposta.

A presença constante da solução apresentada na HQ mais uma vez mostra como a narrativa ajudou a construir a memória dos estudantes quanto ao conceito de "densidade", fornecendo a eles conhecimentos básicos que posteriormente foram usados na resolução de problemas. Os outros onze estudantes, porém, quando confrontados com objeções às teorias próprias que haviam desenvolvido, retornavam àquilo que estava narrativamente estruturado em suas mentes (isso é, a solução das moedas), em vez de melhorarem suas teorias. $\mathrm{O}$ fato de retornarem ao procedimento presente na HQ evidencia duas coisas:

1) Os estudantes ainda não tinham seu conhecimento consolidado o bastante para se apoiarem nele, o que é sinal de que seu processo de aprendizagem ainda estava ocorrendo e que precisavam de mais tempo do que lhes havia sido dado até aquele momento. A atividade de retomada da prova não foi, para esses estudantes, simples aferição do que já sabiam, mas parte do processo de aprendizagem; e

2) A narrativa funcionou como âncora para os estudantes que estavam inseguros de sua posição, reforçando o importante papel que uma HQ pode ter no processo da aprendizagem. Eles não recorreram às informações que lhes foram dadas no modo paradigmático, mas sim à narrativa que leram.

À luz de nossos resultados, acreditamos que os estudantes incorporam a narrativa presente na HQ à sua visão de mundo muito mais facilmente do que costumam incorporar uma informação científica apresentada paradigmaticamente. Como já ressaltado por Soares (2004), o estudante que não aprende, durante as aulas, os conceitos científicos envolvidos na história, provavelmente terá grandes dificuldades de questionar esse conteúdo. Considerando nossos resultados, temos a convicção de que, para surtir um efeito positivo em termos de apropriação de um conceito científico, esse deve ser central na narrativa. No caso da HQ usada nesse trabalho, o conceito estava presente na narrativa, mas a resolução do problema usou elementos que não faziam parte do contexto dos estudantes (as moedas de ouro).
Percebemos que, ao não conseguir organizar narrativamente a sua própria "história", os estudantes recorreram à solução presente na $\mathrm{HQ}$.

Bruner (2001) defende que todo encontro de ensino-aprendizagem é centrado no processo de permitir ao estudante aprender a pensar a partir do que ele já sabe. Sob essa perspectiva, podemos dizer que a experiência com a HQ teve um impacto positivo junto aos estudantes investigados neste trabalho. Ao final da terceira etapa, três dos seis grupos de estudantes (cada um a seu tempo) haviam fornecido uma solução para o problema proposto pela professora, ou seja, $56 \%$ da turma. Consideramos esse resultado bastante expressivo. Para esses 14 estudantes, o conhecimento estruturado pela HQ e pela discussão dessa história durante todo o processo foi suficiente para darem um "passo além" na solução da situação-problema, caracterizando essa atividade como um encontro de ensinoaprendizado (Bruner, 2001).

As aulas relatadas atuaram positivamente na participação dos estudantes, conforme já dito, e alguns casos foram particularmente interessantes. Um deles é o do Estudante P, que normalmente não participava verbalmente das aulas, mas demonstrou interesse e participou em várias oportunidades durante toda a pesquisa, a ponto de pedir silêncio aos colegas durante sua fala. Outro caso que merece ser mencionado é o do Estudante $\mathrm{W}$, que é portador de uma grave deficiência visual. Ele participou ativamente de todos os momentos da atividade. Uma colega leu a HQ para ele e as manifestações que fez ao longo das aulas investigadas nos faz argumentar que ele não só entendeu o enredo, como também entendeu a Ciência presente nesse enredo. Isso constitui uma evidência de que, apesar de a leitura dos quadrinhos ser uma atividade visual, a inclusão acontece se a leitura desperta o interesse do leitor. Pizarro et al. (2011), ao trabalharem com uma HQ intitulada "Jogo do Lixo", já haviam destacado o potencial das HQs para promover o debate em sala de aula. Em nosso trabalho esse potencial ficou evidente, com a participação de estudantes como aconteceu nos casos de $\mathrm{P}$ e W.

\section{Considerações Finais}

De maneira geral, pudemos perceber que, durante todas as etapas da pesquisa, os estudantes espontaneamente se remeteram à solução proposta pelos personagens da história, sempre que se deparavam com um problema semelhante. Isso aconteceu tanto na primeira situação-problema, proposta no dia da leitura da $\mathrm{HQ}$, quanto três meses depois, durante a retomada da questão problema na atividade avaliativa. $\mathrm{O}$ fato de que a $\mathrm{HQ}$ ficou presente na memória desses estudantes pode ser atribuído à natureza narrativa das HQs, que as aproxima da linguagem comum das interações humanas. Além disso, há a possibilidade de que os próprios elementos da narrativa podem levar esse estudante a prestar mais atenção a elementos-chave de um problema, investindo-os de valor emocional e, portanto, retendo-os de forma mais duradoura na memória (Bruner, 2002). 
Portanto, argumentamos que a HQ não representou, para esse grupo de estudantes, simplesmente um meio mais atrativo de inserir os conceitos científicos, mas uma oportunidade de auxiliar na criação de uma narrativa interior, que "acomodou" esses conceitos. Embora as propostas iniciais de resolução de um problema fossem construídas com elementos presentes na HQ e que não estavam disponíveis no mundo real, ou seja, no laboratório da escola, ao serem questionados sobre isso os estudantes foram, aos poucos, se apropriando de um novo modo de pensar uma solução. Ao que nos parece, a HQ facilitou a memória de um procedimento usado pelos personagens e auxiliou na construção de um novo procedimento, para a maior parte dos estudantes. Mesmo aqueles estudantes que tiveram dificuldade em transcender a situação da história e que, por isso, se fixaram no uso das moedas de ouro, são exemplos de como a estrutura narrativa é poderosa na formação de memórias e, nesse sentido, merece a atenção de pesquisadores.

Os resultados aqui encontrados nos levam a crer que as HQs são instrumentos eficazes para auxiliar na aprendizagem, engajando os estudantes na discussão de um conceito e ajudando-os a fazer relações desse conceito com um contexto que, embora guarde algumas semelhanças, traz diferenças significativas.

Em todos os trabalhos já relatados envolvendo HQ no ensino de Ciências, os autores argumentam sobre resultados positivos em termos de aprendizagem quando as HQs foram usadas para trabalhar temas científicos com os estudantes. Pelos dados encontrados em nosso trabalho, sabemos que o entendimento de um conceito exige bem mais que uma HQ. É preciso que o professor use de estratégias específicas para que os estudantes percebam a relação dos conceitos científicos tanto com a história narrada quanto com o contexto.

HQs comerciais, como os quadrinhos Disney ou da Turma da Mônica, são comumente usadas para discutir algum fenômeno químico que esteja presente nessas HQs. Certamente esses quadrinhos comerciais possuem o benefício de envolver os estudantes na atividade. No entanto, consideramos ser importante uma atenção à forma como o conceito científico é apresentado nessas HQs. A formação de concepções alternativas ou de um entendimento equivocado do fato ou fenômeno apresentado na HQ pode se mostrar como um obstáculo para a construção de uma ideia científica. Além disso, caso o conceito não seja importante para a narrativa da história, provavelmente não gerará um interesse emocional no estudante.

A primeira questão que intencionávamos responder com este trabalho se refere ao impacto dos quadrinhos para o ensino de conceitos da Química. Entendemos, agora, que esse impacto foi significativo. Ficou visível que os estudantes se apegaram a elementos que foram investidos de forte valor sentimental na história, e esses elementos eram justamente aqueles que ajudariam os estudantes a compreender o procedimento experimental e o conceito de densidade (como as moedas de ouro, por exemplo). Se a história não dispensasse carga emocional a esses elementos, os estudantes poderiam não os relembrar mais tarde, não alcançando o mesmo nível de impacto em aulas subsequentes. O desafio trazido por esse apego aos elementos marcantes está no fato de que, caso os estudantes não sejam capazes de articular seus próprios recursos para construir sua solução para o problema, eles terminarão resgatando o que lembrarem da história em vez de buscar transcender esses elementos.

A segunda questão referia-se à contribuição desse impacto na apropriação de um conceito científico. Vimos que três grupos de estudantes foram capazes - cada um em seu tempo - de usar o conceito adequadamente na resolução da situação-problema. Portanto, a nosso ver, há uma contribuição significativa na aprendizagem.

Na terceira questão tínhamos a intenção de verificar se os elementos presentes na HQ seriam relembrados pelos estudantes, em atividade posterior. Para essa questão podemos afirmar categoricamente que sim. $\mathrm{O}$ grupo de estudantes participantes recorreu inúmeras vezes aos elementos presentes na HQ para tentar encontrar uma solução adequada para a situação-problema, tanto durante a prova quanto no momento em que ela foi retomada, praticamente três meses depois.

Percebemos que as vantagens e desvantagens dos quadrinhos vão muito além da trama da história, do interesse que geram e da arte dos mesmos. Acreditamos que quadrinistas interessados em contribuir com o ensino de Ciências poderão utilizar os resultados aqui apresentados para a criação de materiais cada vez mais adequados a esse objetivo, inclusive a autora da HQ em questão e os autores Gama e Francisco Junior (2014), que já se iniciaram nessa tarefa. Temos claro, porém, a necessidade de ampliar essa pesquisa, aprofundando a respeito de narrativas a serem usados em sala de aula, dos elementos que devem ou não figurar nelas e sobre o alcance do texto e da imagem presente em uma $\mathrm{HQ}$, por exemplo.

Com isso, somos favoráveis ao uso de HQs em aulas de Ciências, já que a HQ utilizada se mostrou como uma aliada ao trabalho docente, principalmente por ter engajado os estudantes nas aulas e na discussão de situações-problema que envolviam conceitos químicos. Ressaltamos, no entanto, que uma atenção maior deve ser dada à seleção da história e da atividade a ser desenvolvida pelo professor para transformar uma história "fictícia" em ferramenta de aprendizagem em sala de aula. Temos a expectativa que, no futuro, a mídia dos quadrinhos seja aperfeiçoada para ter uma presença maior nas aulas de Ciências, contribuindo não só com o interesse e a motivação dos estudantes quanto ao assunto tratado, mas também com o processo de aprendizagem em si.

\section{Notas}

1. Blog de tirinhas Bram \& Vlad. Disponível em http:// bramevlad.blogspot.com.br/, acessada em Março 2018.

2. Publicação de imprensa alternativa, geralmente produzida por e para fãs, dedicada a manifestações culturais, como é o caso dos quadrinhos. 
3. A História em Quadrinhos usada nesse trabalho está disponível em http://bramevlad.blogspot.com/2017/06/alice-e-estatua-misteriosa.html, acessada em Março 2018.

4. A Copa do Mundo de futebol de 2014 foi realizada no Brasil e, em função dos jogos realizados na cidade de Belo Horizonte, o calendário escolar sofreu alterações.

\section{Referências}

BARTLETT, F. Remembering: a study in experimental and social psychology. Cambridge: Cambridge University Press, 1932.

BRUNER, J. A cultura da educação. Porto Alegre: Artes Médicas, 2001. . Atos de significação. Porto Alegre: Artes Médicas, 1997. Fabricando histórias: direito, literatura, vida. São Paulo: Letra e Voz, 2010.

Realidade mental, mundos possíveis. Porto Alegre: Artes Médicas, 2002.

. The narrative construction of reality. Critical Inquiry, v. 18 , n. 1, p. 1-12, 1991.

CARUSO, F. e SILVEIRA, C. Quadrinhos para a cidadania. História, Ciências, Saúde - Manguinhos, v. 16, n. 1, p. 217-236, 2009.

CHINELli, M. V.; FERREIRA, M. V. S. e AGUiAR, L. E. V. Epistemologia em sala de aula: a natureza da ciência e da atividade científica na prática profissional de professores de ciências. Ciência \& Educação, v. 16, n. 1, p. 17-35, 2010.

COUPIERE, P.; DESTEFANIS, P.; FRANÇOIS, E.; HORN, M.; MOLITERNI, C. e TALABOT, G. G. Histórias em quadrinhos e comunicação de massa. São Paulo: MASP, 1970.

EISNER, W. Quadrinhos e arte sequencial. São Paulo: Martins Fontes, 1989.

GAMA, E. J. S. e FRANCISCO JUNIOR, W. E. Avaliando uma história em quadrinhos produzida para o ensino de química e educação ambiental. In: Anais do XVII Encontro Nacional de Ensino de Química. Ouro Preto, MG, 2014.

GLASER, B. G. e STRAUSS, A. L. The discovery of grounded theory: strategies for qualitative research. New York: Aldine de Gruyter, 1967.

LÜDKE, M. e ANDRÉ, M. E. D. A. Pesquisa em educação: abordagens qualitativas. São Paulo: EPU, 1986.

MANDLER, J. Stories, scripts and scenes: aspects of schema theory. Hillsdale: L. Erlbaum Associates, 1984.

MALAFAIA, G.; BÁRBARA, V. F. e RODRIGUES, A. S. L. Análise das concepções e opiniões de discentes sobre o ensino da biologia. Revista Eletrônica de Educação, v. 4, n. 2, nov. 2010.

McClOUD, S. Desvendando os quadrinhos. São Paulo: Makron Books, 1995.

MIGUÊZ, L. S.; CASTRO, L. M. F. e ARAUJO, G. C. Uma história em quadrinhos - as aventuras de Hélio em: estudando o ciclo do nitrogênio e o princípio de Le Chatelier. In: Anais do XVII Encontro Nacional de Ensino de Química. Florianópolis, SC, 2016.

MUCCHIELli, R. Les méthodes qualitatives. Paris: Presses Universitaires de France, 1991.
OLIVEIRA, R. D. V. L.; DELOU, C. M. C. e CÔRTES, C. E. S. O ensino de estrutura atômica usando uma história em quadrinhos. In: Anais do XV Encontro Nacional de Ensino de Química. Brasília, DF, 2010.

PIZARRO, M. V. Histórias em quadrinhos e o ensino de ciências nas séries iniciais: estabelecendo relações para o ensino de conteúdos curriculares procedimentais. Dissertação (Mestrado em Educação para a Ciência). Universidade Estadual Paulista, Bauru, 2009a.

. As histórias em quadrinhos como linguagem e recurso didático no ensino de ciências. In: Atas do VII Encontro Nacional de Pesquisa em Educação em Ciências (VII ENPEC). Florianópolis, SC, 2009b.

PIZARRO, M. V.; IACHEL, G. e SANCHES, I. A. S. Discussões sobre a seleção de lixo reciclável nos anos iniciais: uma proposta em alfabetização científica a partir do trabalho com histórias em quadrinhos no $2^{\circ}$ ano do ensino fundamental. In: Atas do VII Encontro Nacional de Pesquisa em Educação em Ciências (VIII ENPEC). Campinas, SP, 2011.

RODRIGUES, A. A. D. e QUADROS, A. L. O uso de histórias em quadrinhos no ensino de química: relatando uma experiência. In: Anais do XVII Encontro Nacional de Ensino de Química. Ouro Preto, MG, 2014.

SANTOS, P. N. e AQUINO, K. A. S. Produção de histórias em quadrinhos no ensino de química orgânica: a química dos perfumes como temática. In: Anais do XV Encontro Nacional de Ensino de Química. Brasília, DF, 2010.

SANTOS, D. O.; LIMA, J. P. M. e SILVA FILHO, J. C. A. Química do ovo: uma HQ para o ensino de Química. In: Anais do XV Encontro Nacional de Ensino de Química. Brasília, DF, 2010.

SANTOS, J. S.; GUEDES, J. T.; OLIVEIRA, F. S.; SANTOS, L. D. e CRUZ, M. C. Abordagem do comportamento ácido e básico nas frutas através das histórias em quadrinhos (HQs). In: Anais do XVII Encontro Nacional de Ensino de Química. Ouro Preto, MG, 2014.

SOARES, A. H. M. A química e a imagem da ciência e dos cientistas na banda desenhada: uma análise de livros de B. D. e de opiniões e interpretações de investigadores, professores de C. F. Q. e estudantes do $3^{\circ}$ ciclo. Dissertação (Mestrado em Química - Especialização em Ensino). Universidade do Minho, Braga, Portugal, 2004. Disponível em <http://hdl.handle.net/1822/590>, acessada em Março 2018.

TESTONI, L. A. Um corpo que cai: histórias em quadrinhos no ensino de física. Dissertação (Mestrado em Educação). Universidade de São Paulo, São Paulo, 2004.

UCHÔA, A. M.; FRANCISCO JUNIOR, W. E. e FRANCISCO, W. Produção e avaliação de uma história em quadrinhos para o ensino de química. In: Anais do XVI Encontro Nacional de Ensino de Química. Salvador, BA, 2012.

VERGUEIRO, W. e RAMOS, P. Quadrinhos na educação. São Paulo: Editora Contexto, 2009.

VERGUEIRO, W. e SANTOS, R. E. Histórias em quadrinhos no processo de aprendizado: da teoria à prática. EccoS Revista Científica, n. 27, p. 81-95, jan./abr. 2012.

YIN. R. K. Estudo de caso: planejamento e métodos. $3^{\mathrm{a}}$ ed. Porto Alegre: Bookman, 2005. 